\title{
Sustainable futures in the context of architectural design of hospitals
}

\author{
Irina Bulakh, ${ }^{1, *}$,Margaryta Didichenko ${ }^{1}$, Olena Kozakova ${ }^{2}$, and Olena Chala $^{2}$ \\ ${ }^{1}$ Kyiv National University of Construction and Architecture, Department of Design architectural environment, Kyiv, \\ Ukraine \\ ${ }^{2}$ Kyiv National University of Construction and Architecture, Department of information technologies in architecture, \\ Kyiv, Ukraine
}

\begin{abstract}
The problems of necessity of sustainable and ecological approaches in architectural design of hospitals are raised in the research. The best international experience of designing and operating hospitals designed on the principles of sustainable development is considered. Examples and implementation examples of healthcare institutions integrating energy efficient technologies are analyzed and illustrated: natural ventilation, solar panels, rainwater collection, filtration and reuse of wastewater, greening of the roof and walls, sun protection, aerodynamic volumetric and spatial form. Studying and using the proven experience of the best examples of ecological hospital buildings, recognized and certified at the highest levels of the world institutions for the development of a sustainable future, will allow Ukraine to create the conditions for solving the crisis both in the sphere of health care and in the ecologically preserved environment of the country.
\end{abstract}

\section{Introduction}

In modern civilization, nearly half of the total energy consumption in developed countries falls on architectural buildings and a fourth on transport. From this point of view, the role of the architect in the design of buildings for various purposes, including medical, in the issue of a sustainable future world, individual state or human settlement, is quite significant. Undoubtedly, only architects are unable to solve all the diversity of the world's environmental problems [1-3]. The architect, as the creator, has the opportunity to design innovative buildings that are able to use the minimum amount of traditional energy sources, providing their own needs with the help of renewable natural energy (Fig. 1, Fig. 2). Also, thanks to rational and proper urban planning, the architect is able to influence and correct traffic flows, reducing the negative impact on the already polluted environmental situation, particular in Ukraine.

Starting from the location and functional purpose of the building, the choice of its structural system, flexibility, technological resources of construction and subsequent operation, orientation at the site of design, and ending with the selected planning and volume-space form, engineering (heating, conditioning, characteristics) building materials - all this set of parameters chosen by the architect directly affects the amount of energy required for construction, operation and subsequent technical maintenance of building [4-6]. Outlined issues are of particular importance in the context of designing healthcare facilities in Ukraine. This is due to the prolonged economic and energy crisis in our country, as well as the fact that most of the architectural and urban system of medical establishments in Ukraine was built in a typical industrial way in Soviet times and today in all respects contradicts energy-efficient requirements as domestic and the world (Fig. 3, Fig. 4, Fig. 5) [4-7]. Build on the ongoing reform of the Ukrainian medical system, the issue of finding and using sustainable architectural solutions in the reconstruction and new development of medical facilities of any scale is becoming increasingly relevant. Therefore, an understanding of the harmony of the environment and the modern architecture of healthcare facilities should be reflected in the emergence of health care projects that integrate best practices in energy-efficient construction, opening a new page in the evolution of architectural design in health care facilities and in the overall history of world design and construction.

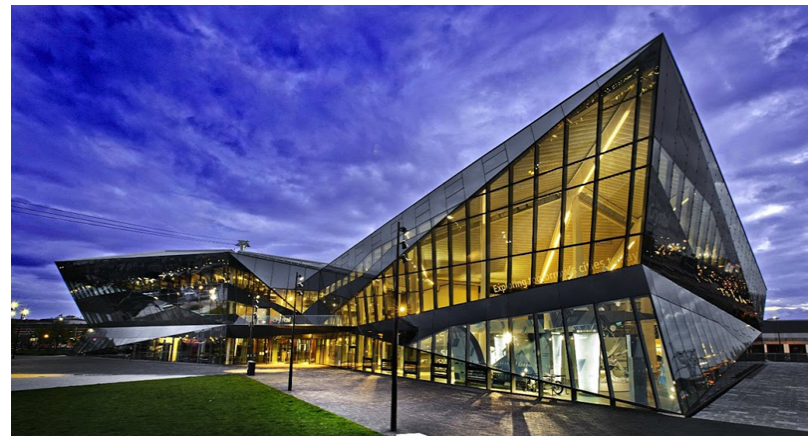

Fig. 1. The Crystal, Wilkinson Eyre Architects, London.

\footnotetext{
* Corresponding author: bulakh.iv@knuba.edu.ua
} 


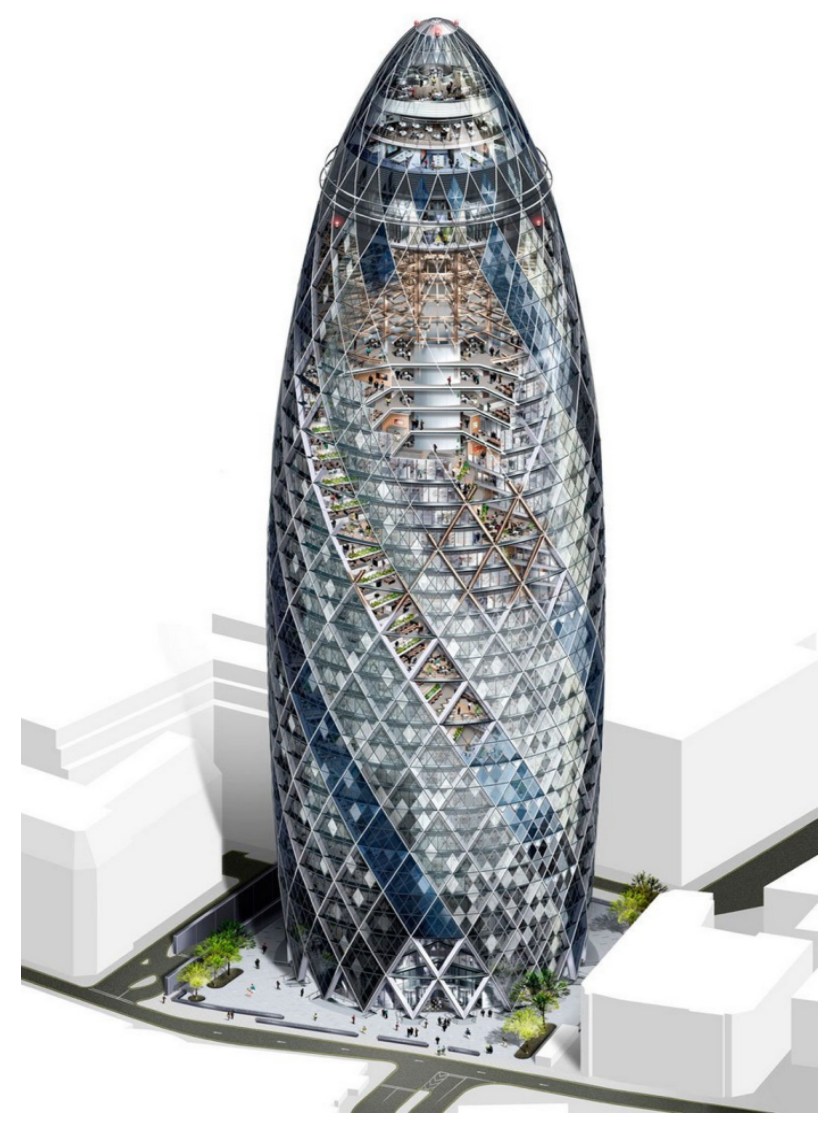

Fig. 2. 30 St Mary Axe / Look Inside, Foster + Partners.

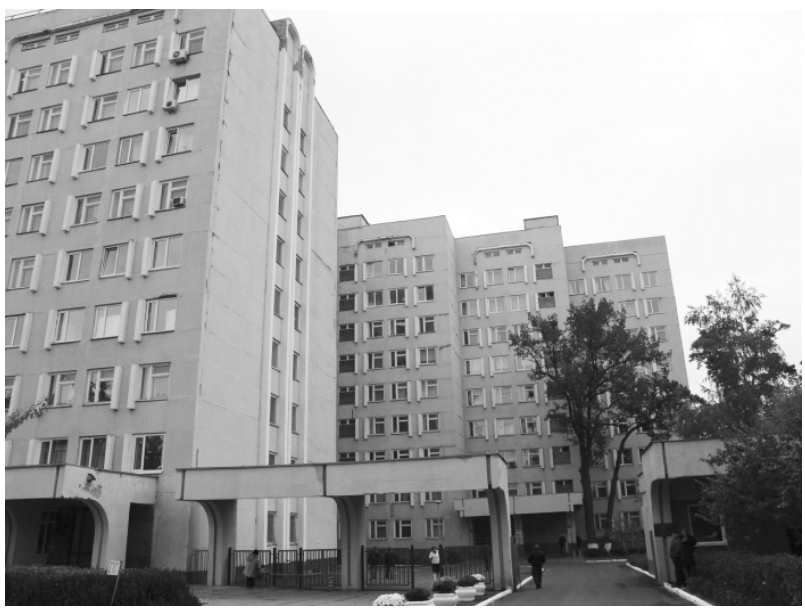

Fig. 3. Kyiv City Clinical Oncological Centre.

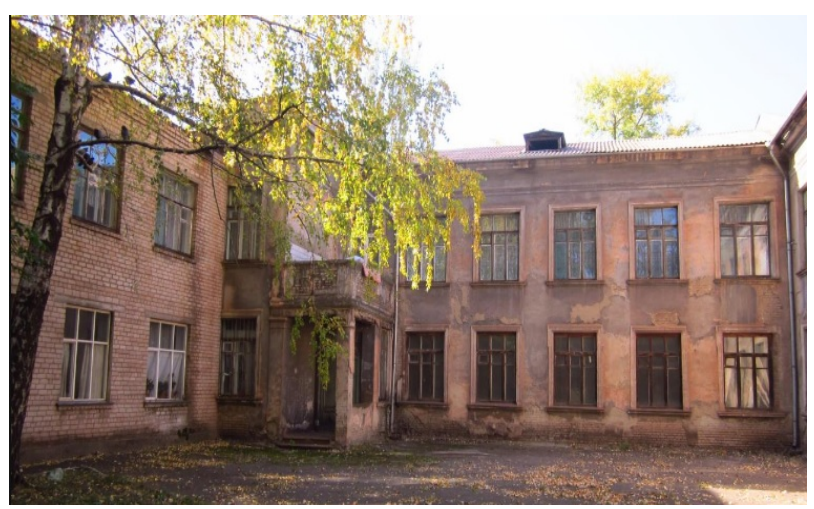

Fig. 4. Hospital building No.3, Kryvyi Rih.

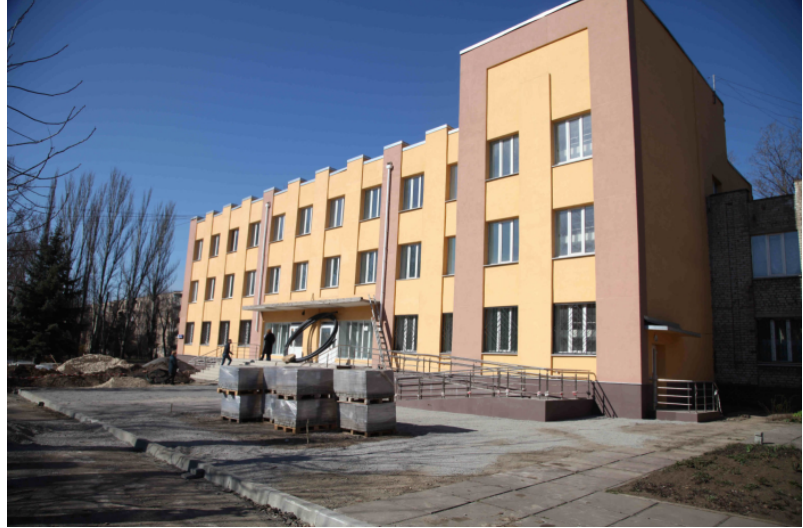

Fig. 5. Children's Hospital No.2, Kryvyi Rih.

\section{Statement of the main material}

Today our country is dependent on energy imports, ensuring affordable and reliable energy supply is a political priority for Ukraine. In Ukraine, energy consumption, the ratio of energy consumption to energy production, is about three times higher than in EU countries. Obsolete infrastructure and energy supply systems, as well as dependence on energy imports from abroad, have led to a significant increase in energy prices of [8-11]. In this aspect, the issue of accessibility and security of energy supply has become a priority for the Government of Ukraine, which primarily supports energy savings in the budget sector. The most energyintensive public facilities include more than 1,000 Ukrainian hospitals with nearly 430,000 beds. Some hospitals spend up to 20 percent or more of their budget on energy. The outlined situation means that healthcare institutions are under pressure from high energy prices. First of all, the quality of medical services suffers from this: hospitals cannot buy important medical products in sufficient quantity, upgrade equipment, carry out modernization and reorganization, and engage in research activities.

In order to reduce costs, hospitals should conserve energy reasonably and where appropriate. The recent rapid rise in energy prices has led to significant economic pressures on health care facilities and limited their financial capacity, leading to a decline in the quality of health care services [12-14]. Due to considerable energy consumption, hospitals do not always manage to reach patient comfort standards and indoor temperatures remain too low in winter. Energy upgrades, mainly involving no or small investments, are not currently being implemented. The potential for energy savings in hospitals is generally high, but hospital staff often lack the resources and knowledge to implement it. In addition, there is a lack of consultation on energy efficiency and financial capacity [15-20]. Therefore, considerable attention should be paid to the energy aspect of the sustainable development of architectural solutions.

From the perspective of sustainable future architecture for reconstruction and new development at Ukrainian healthcare institutions, it is advisable to refer 
to the design and operation experience of architecturalenvironmental complex of $\mathrm{Ng}$ Teng Fong Innovative Singapore Hospital (NTFGH) and Jurong Public Hospital ( $\mathrm{JCH})$, which have received numerous awards in energy competitions, ratings and certifications and energy efficiency and certification designing health facilities worldwide (Fig. 6).

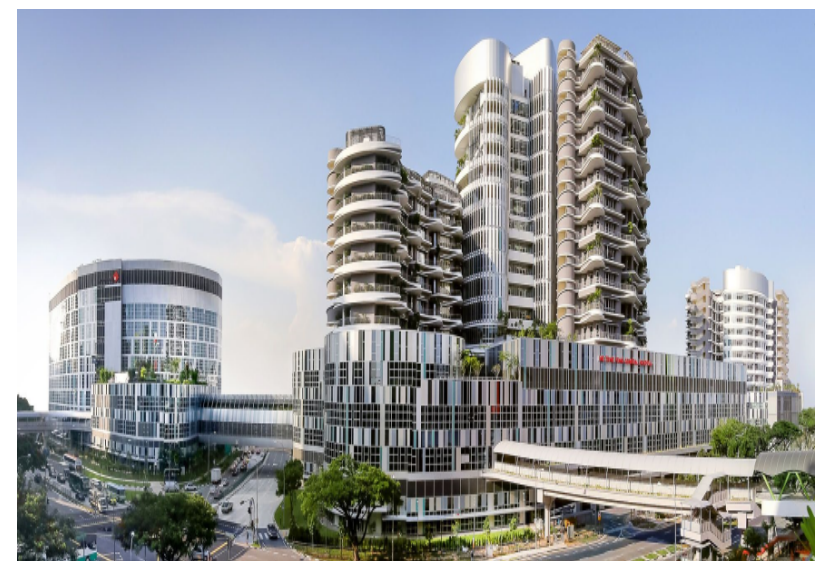

Fig. 6. General view of the hospital complex Ng Teng Fong (NTFGH) \& Jurong (JCH).

Both hospitals, with a total capacity of 1,100 wards, are the first in the country to be built under the new mandate of the Ministry of Health of Singapore (part of the Progressive Health Master Plan 2020), aimed at providing the state with patient-centred services in a comprehensive mode, that is, by combining emergency services and outpatient specialities with a general public hospital. In this sense, the complex of NTFGH and JCH hospitals, functionally and planning integrated within one territorial area, serves as a good model for both Ukrainian architects and health care organizers in the context of the global trend of combination and concentration in one building spectrum of medical services (primary, secondary and tertiary levels of medical care) (Fig. 7) [19-22].

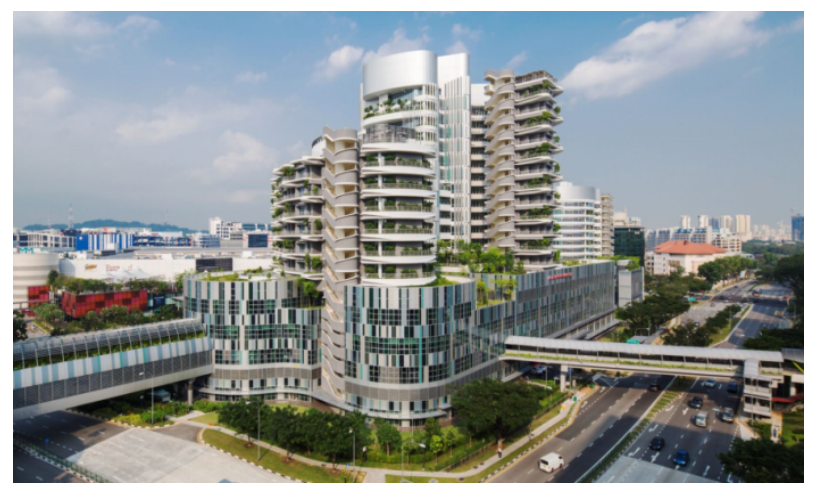

Fig. 7. Accommodation of the hospital complex $\mathrm{Ng}$ Teng Fong (NTFGH) \& Jurong (JCH) in the urban area.

NTFGH 8th- and 16-story Regional Emergency Hospital and 12-story JCH Hospital, designed to assist and provide long-term rehabilitation and palliative care, built at 2015 in a beautiful 1.9 million-square-foot urban area feet. Delivering energy intensity (EUI) of $72 \mathrm{kWh}$ per square foot per year, the innovative energy-efficient design of the hospital complex reduced energy costs by 38 percent compared to other Singapore hospitals and 69 percent less than the average US hospital. Designed according to Singapore's Green Mark Platinum standards, which certify buildings based on energy efficiency, water efficiency, environmental protection, indoor environment quality and other environmental features - the project was awarded one of the COTE Top 10 awards by the American Institute of Environmental Architects (COTE). The Top Ten Award recognizes the sustainable development of design around the world and confirms that the project meets COTE criteria for social, economic and environmental value. It should be noted that $\mathrm{Ng}$ Teng Fong and Jurong Hospitals have become one of the few health projects to receive this award.

The design features of the NTFGH and JCH hospital complex was developed using the key-principles of sustainable architecture include design approaches below. They include a well-considered design approach to the specific characteristics of the external environment, the ability to individually open windows and the natural ventilation of wards, depending on patients' wishes. Both hospital buildings are equipped with $90 \mathrm{~kW}$ photovoltaic arrays, specially designed to compensate for illumination of the treatment facility, as well as heat recovery, heat pumps and heat exchangers with streamlined coils to maintain the required operating temperatures. The cooling system's metering and monitoring system monitor current energy use, solar thermal collectors provide 100 percent of hot water demand, and the filtration system treats wastewater for reuse. The hospital complex uses rainwater collection, LED lighting, daylight and occupancy sensors, a building management system with monitoring, occupancy levels and sleep modes to save energy. Each ward on NTFGH and JCH floors with good window views is linked to the geometry of the floor plans (Fig. 8). Each floor of the Singapore hospital complex, unlike the traditionally Ukrainian linear rectangular geometric solutions, received fan-shaped shapes, with bed placements being calculated and rotated at an individual angle, thus providing communication through a window opening overlooking the street (Fig. 9, Fig. 10).

Ultimately, the unique aerodynamic shape of the hospitals, combined with unidirectional corridors and funnel-shaped floor profiles, maximizes wind flow. Special consideration should be given to the regional features of the area, which managed to achieve natural ventilation for 70 percent of the buildings of the hospital - the team of architects took into account the presence of breezes characteristic of the area during the two-year monsoon seasons in Singapore. Thus, the individual volumetric shape of the NTFGH and JCH hospitals, combined with the aerodynamic modelling of the projections of the overlapping floor slabs and the calculated distances between the window openings on both sides of the wards, made it possible to provide efficient and free ventilation with natural wind flows. The result is also that 82 percent of hospital hospitals are passively cooled and naturally ventilated with a small 
percentage of mechanical ventilation coming from ceiling and exhaust fans. During the fog season in Singapore, the windows of hospitals are closed and both buildings use a centralized air filtration system. The integration of the naturally ventilated design of the hospital complex has reduced mechanical cooling by 70 percent, as well as installed smaller cooling towers that use filtered wastewater and selected water from the airconditioning system, allowing for more cycles of water reuse.

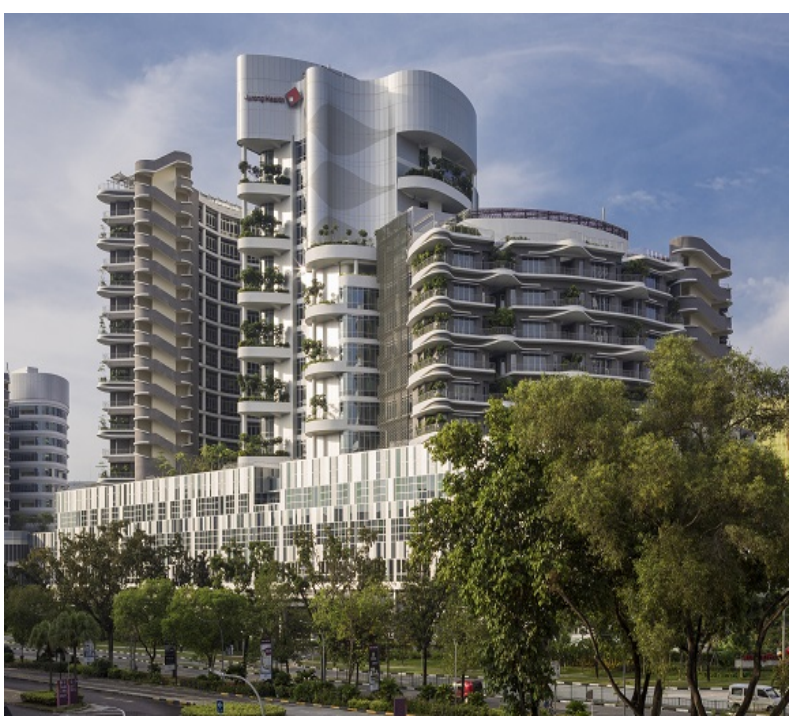

Fig. 8. Fan-shaped outlines in the formation of floorboards and plans of the hospital complex Ng Teng Fong (NTFGH) \& Jurong $(\mathrm{JCH})$.

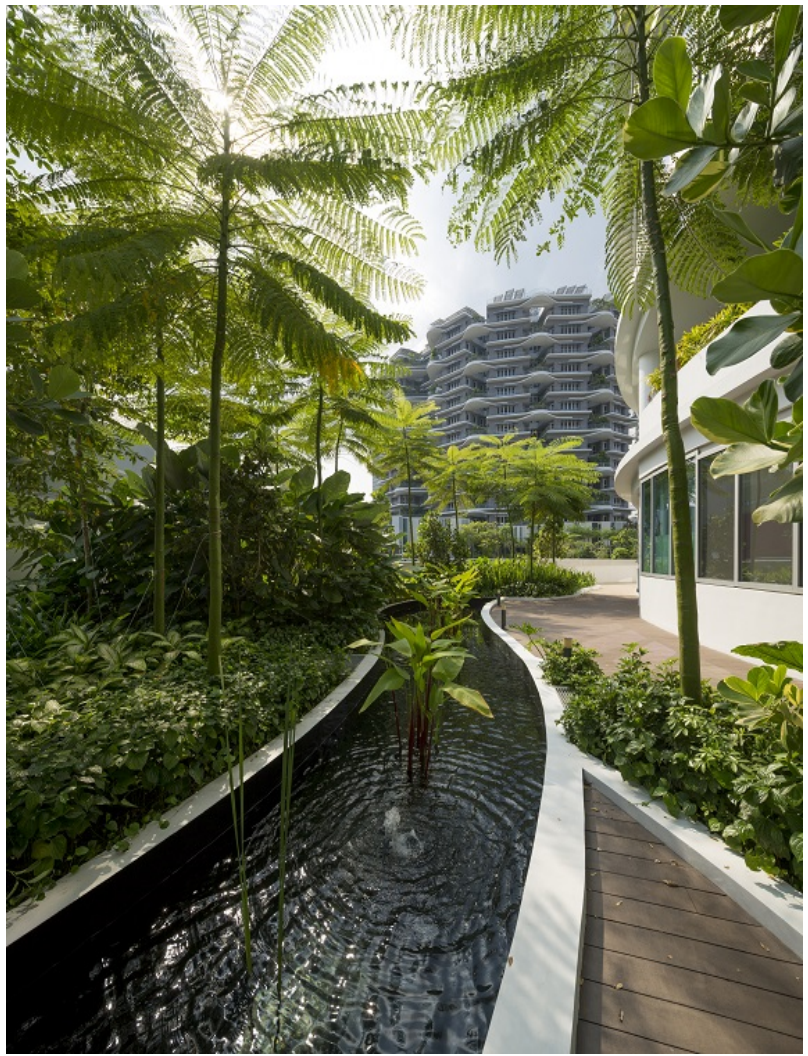

Fig. 9. Exterior and windows from the hospital complex $\mathrm{Ng}$ Teng Fong (NTFGH) \& Jurong (JCH).

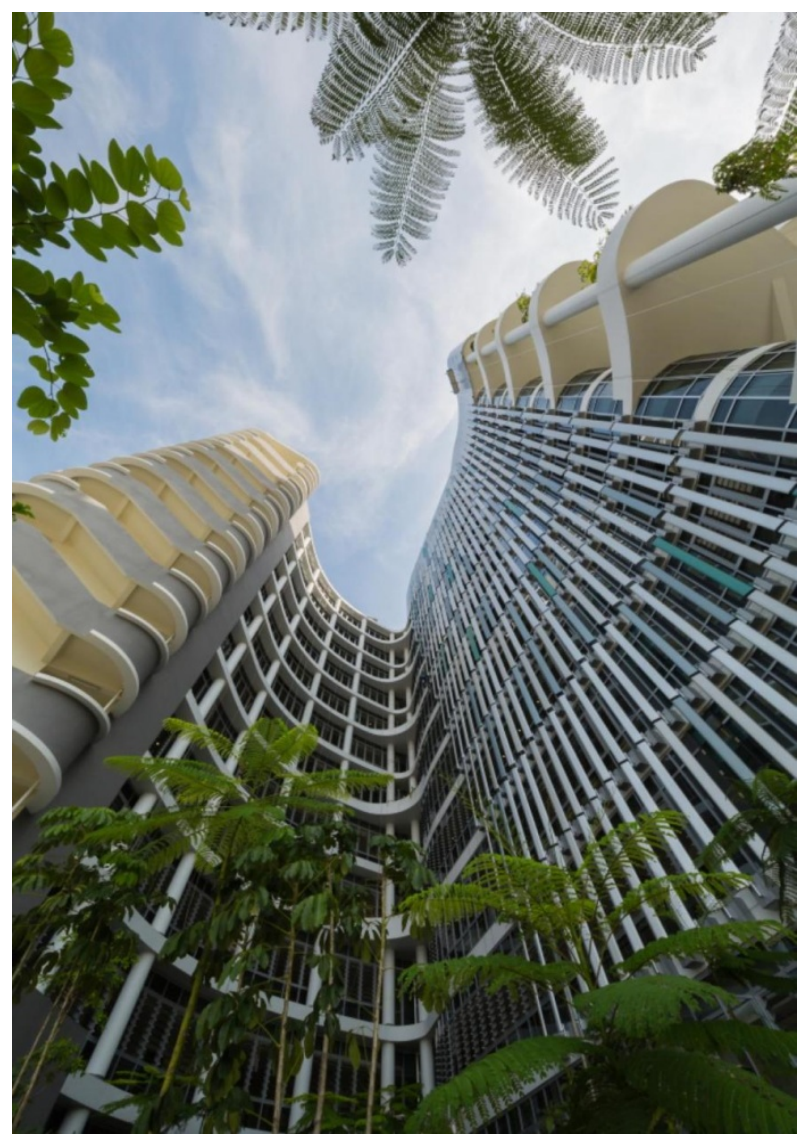

Fig.10. Exterior of hospital complex $\mathrm{Ng}$ Teng Fong (NTFGH) \& Jurong $(\mathrm{JCH})$

In the case of hospital facilities design, the issue of the spread of hospital-acquired infections is of particular importance. In this sense, to design infectious control in the initial design phase, the architectural team used computer computing and simulation models to accurately determine wind flow directions and to ensure that the wind would not pass through several patients and spread infectious pollution. As a result, in the hospital wards, due to the correct size and location of the windows, it is ensured that the wind passed through the bed of only one patient before leaving the building. Another resolved design issue was that with a lot of daylight and ventilation coming into the hospital building, it was necessary to find "reasonable" shading to prevent sunlight and glare.

Architects took advantage of the geographical features of Singapore's location near the equator and the position of the sun changes slightly throughout the year at all times of the year, making the sun's shading plan relatively easy to create. The project envisages three levels of shading of the sun: large projections from concrete floor slabs, blinds with integrated horizontal and vertical slats, as well as the sun screens (Fig. 11, Fig. 12).

The latter provide shading for about 60 percent of the facades where patients' wards and staff rooms are located. Also, the presence of vegetation on the roof and near the windows on several floors of both buildings is considered an element of theoretical shading, with the additional possibility of cooling the ambient temperature 
inside the buildings, absorption and filtration of pollutants (Fig. 13, Fig. 14, Fig. 15, Fig. 16). Other sustainable environmental strategies used in NTFGH and $\mathrm{JCH}$ include water-saving plumbing equipment and rainwater accumulation systems that help to irrigate a large area of landscaping.

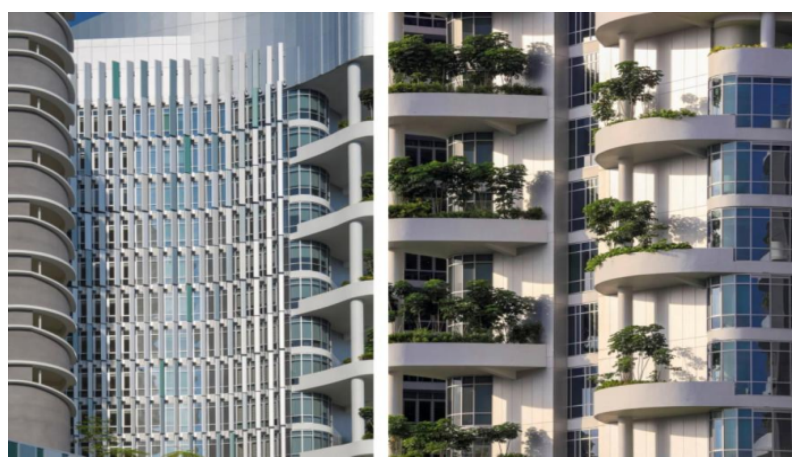

Fig. 11. Use of sunscreen in a hospital complex Ng Teng Fong (NTFGH) \& Jurong (JCH).

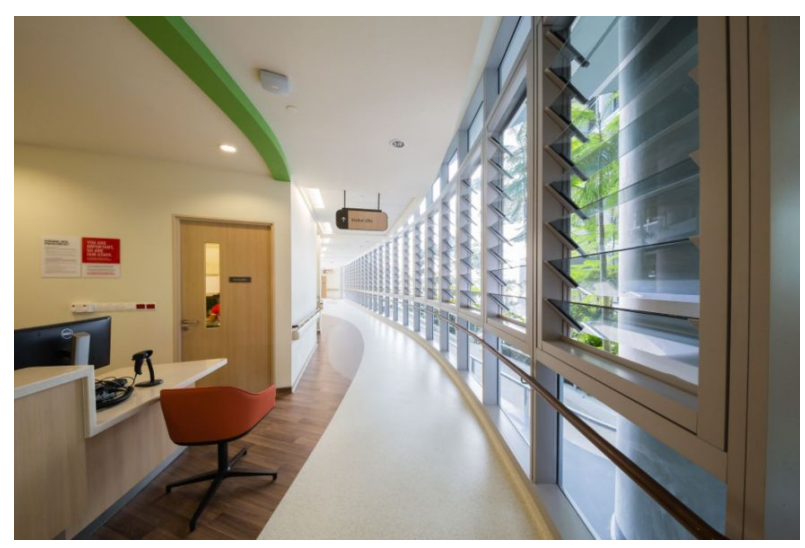

Fig. 12. Sun blinds in hospitals interior $\mathrm{Ng}$ Teng Fong (NTFGH) \& Jurong (JCH).

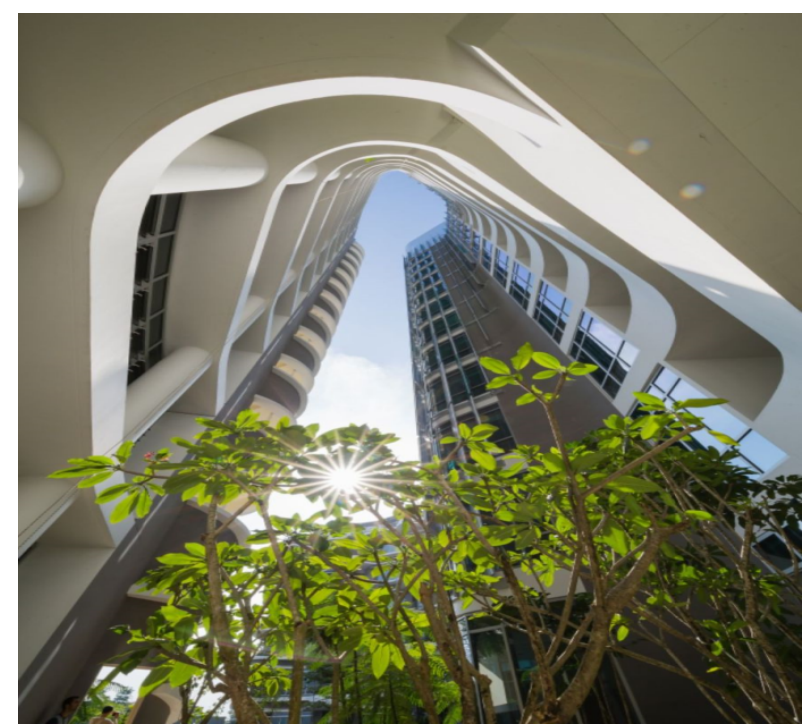

Fig. 13. Exterior view of hospital complex $\mathrm{Ng}$ Teng Fong (NTFGH) \& Jurong (JCH).

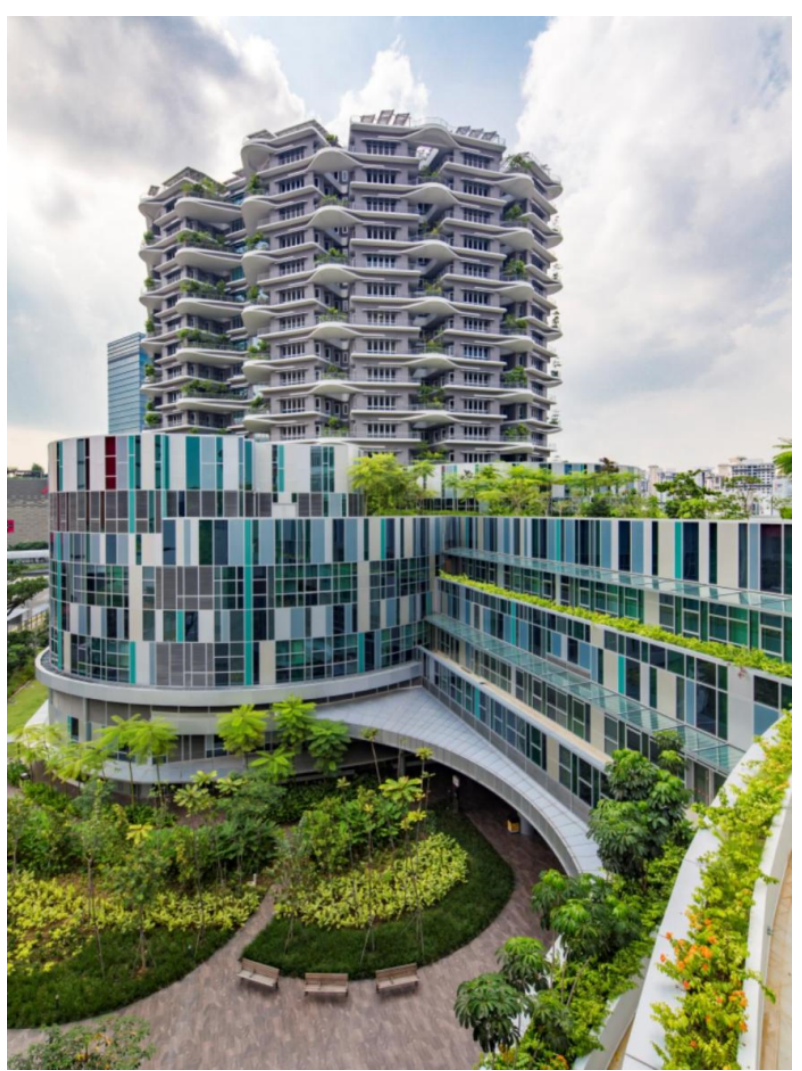

Fig. 14. Active use of landscaping in hospitals $\mathrm{Ng}$ Teng Fong (NTFGH) \& Jurong (JCH).

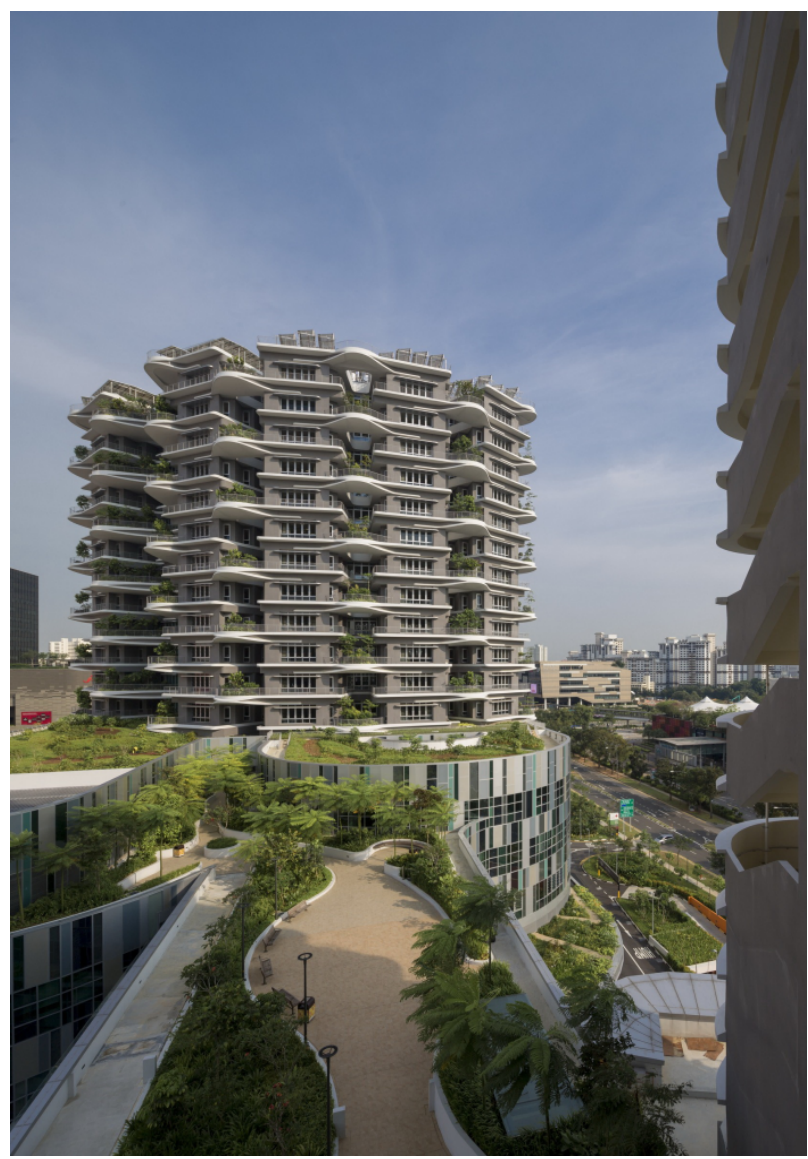

Fig. 15. Hospital in an urban environment. 


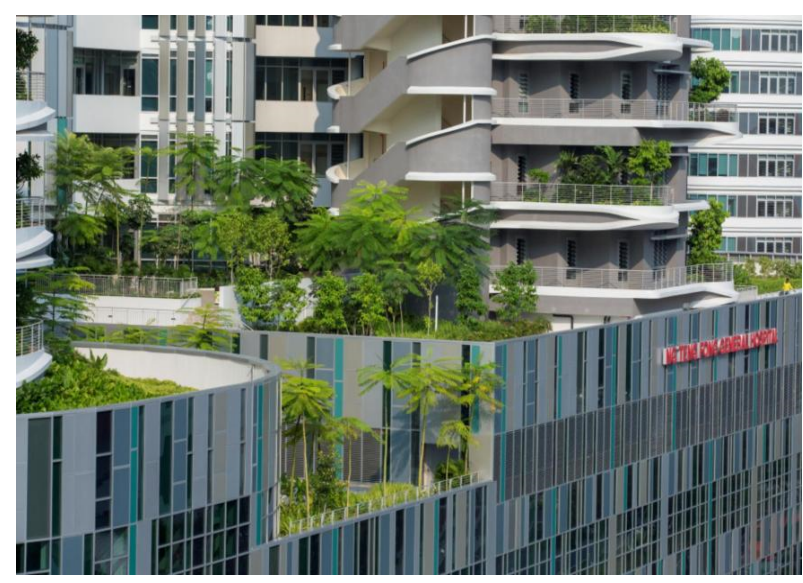

Fig. 16. Implementation of green roofs.

\section{Conclusion}

Integration of principles of sustainable development in architectural design of hospitals is of particular importance for Ukraine - using leading foreign experience, advanced energy-efficient engineering, taking into account the regional geographic and climatic features of our area, the architect, as the main "conductor", has the opportunity to solve several problems at once. On the one hand, we are talking about the ecological spectrum of designing and construction of medical establishments (saving traditional energy sources, reducing the harmful impact on the environment, energy autonomy of the building, etc.), on the other - a significant economic effect and, as a consequence, the opportunity to spend saved financial resources. for the development and improvement of the healthcare sector. According to the successful example of sustainable design of a medical complex in Singapore, it is considered advisable to lay down project solutions that strict meet international standards for sustainable architecture at the design stage. However, in the reconstruction phase and within the limited budget, considerable attention should be paid to the following aspects. First, it is necessary to increase the energy independence of the buildings by providing them with alternative energy sources, in particular solar collectors, which can fully or partially (depending on the region and spatial characteristics of the complex) solve the issue of electricity consumption and space heating. As a great part of medical buildings in Ukraine have typical flat roof designs, this solution can be effectively implemented without significant intervention at the architectural and design-built system. The second aspect is the contextual relevance of the facade solution to the natural-climatic conditions of the planning region. In Ukraine is a long heating season, which necessitates the implementation of energy-efficient solutions like the facade warming and sealing the building by the corresponding indicators glazing. Another aspect is the rational use of water resources - the collection and using of rainwater, as well as the filtration system of used water, which allows for more cycles of its reuse. The fourth aspect is the provision of a natural independent ventilation system for each unit, which reduces the burden on energy consumption and improves the microclimate of the premises, which is necessary for successful treatment and healthcare care. The highlighted aspects are of paramount importance for the modernization of existing medical facilities and their consistency with sustainable design principles.

\section{References}

1. Y. Tabunschikov, M. Brodach, N. Shilkin, Energyefficient high-rise building, 3, p. 8 (2002)

2. Y. Tabunschikov, Mathematical models of thermal conditions in buildings (CRC Press, 1993)

3. Y. Tabunschikov, M. Brodach, Scientific principles of designing energy-efficient buildings. ABOK 1, (2008)

4. I. V. Bulakh, Common Features of Architectural Design of the Medical Purpose Building. Science \& Technique 18(4), 311-318 (2019). doi:10.21122/2227-1031-2019-18-4-311-318

5. I. V. Bulakh, Artistic and Aesthetic Formation and Evolution of Architectural and Urban Planning Space. Science and Innovation 15(5), 57-66 (2019). doi: $10.15407 /$ scine 15.05 .057

6. A. Holstov, G. Farmer, B. Bridgens, Sustainable Materialisation of Responsive Architecture. Sustainability $\quad 9, \quad 435 \quad$ (2017). doi:10.3390/su9030435

7. H. Salleh, N.A. Mohamed Sabli, A. Shah Ali, M. Alshawi, Performance Evaluation for IT/IS Implementation in Organisation: Preliminary New IT/IS Capability Evaluation (NICE) Model. Journal of Design and the Built Environment 9(1), 75-88 (2011)

8. M. A. Bengochea Escribano, P. A. López Jiménez, G. López Patiño, M. Mora Pérez, Cuantificación de la eficiencia de la fachada cerámica ventilada mediante técnicas de la mecánica de fluidos computacional. Boletín de la Sociedad Española de Cerámica y Vidrio 50(2), 99-108 (2011). doi:10.3989/cyv.142011

9. A. Wierzbicka, E. Pedersen, R. Persson, B. Nordquist, K. Stålne, C. Gao, Healthy Indoor Environments: The Need for a Holistic Approach. International Journal of Environmental Research and Public Health 15(9), 1874 (2018). doi:10.3390/ijerph15091874

10. K. Ren, L. Xu, Dataset on energy efficiency assessment and measurement method for childfriendly space in cold residential area. Data in Brief 14(C), 148-155 doi:10.1016/j.dib.2017.07.032

(2017).

11. J.A. Fadamiro, J.A. Adedeji, An overview of collapse of buildings in Nigeria: a medico-spatial analysis. Journal of Architecture and Built Environment 40(2), 53-62 (2013)

12. M.F.S. Van der Ham, S. Zlatanova, E. Verbree, R. Voûte, Real time localization of assets in 
hospitals using quuppa indoor positioning technology. Remote Sensing and Spatial Information Sciences IV-4/W1, 105-110 (2016). doi:10.5194/isprs-annals-IV-4-W1-105-2016

13. M. Spikman, D. Van Dijk, Comparison of the energy performance of buildings in the EU. Energy saving 5, 43-45 (2009)

14. R.C.G.M. Loonen, M. Trčka, D. Costola, J.L.M. Hensen, Climate Adaptive Building Shells: State of the Art and Future Challenges. Renewable and Sustainable Energy Reviews 25, 483-493 (2013). doi:10.1016/j.rser.2013.04.016

15. R. Loonen, A. Khairulina, J. Hensen, Bioadaptive shell of buildings. High-tech buildings 3(3-3), 5057 (2014)

16. S. Reichert, A. Menges, D. Correa, Meteorosensitive Architecture: Biomimetic Building Skins Based on Materially Embedded and Hygroscopically Enabled Responsiveness. Computer-Aided Design 60, 50-59 (2015). doi:10.1016/j.cad.2014.02.010

17. B.D. Hatton, I. Wheeldon, M. J. Hancock, M. Kolle, J. Aizenberg, D.B. Ingber, An Artificial Vasculature for Adaptive Thermal Control of Windows. Solar Energy Materials and Solar Cells 117, 429-436 (2013). doi:10.1016/j.solmat.2013.06.027

18. The Centre for Health Design (2020), https://www.healthdesign.org. Accessed 21 Mar 2020

19. Now or Never: IEA Energy Technology Perspectives 2008 shows pathways to sustained economic growth based on clean and affordable energy technology (2008), https://www.iea.org/news/now-or-never-iea-energytechnology-perspectives-2008-shows-pathways-tosustained-economic-growth-based-on-clean-andaffordable-energy-technology. Accessed 21 Mar 2020

20. B. Nordquist, S. Elfborg, A. Vrbanjac, P. Wallentén, J. Stein, Energy saving by adding a glass-façade to a brick building, in Central Europe towards Sustainable Building, Prague, Czech Technical University in Prague, 2013, https://www.lunduniversity.lu.se/lup/publication/e3 918b4c-7f6c-4fd7-8c42-da9ac8e94c71. Accessed 28 Nov 2019

21. WSP, Ng Teng Fong General Hospital and Jurong Community Hospital, Singapore (2020), https://www.wsp.com/en-CN/projects/ng-teng-fonggeneral-hospital-singapore. Accessed 21 Mar 2020

22. AIA COTE selected $\mathrm{Ng}$ Teng Fong General Hospital for sustainable design excellence for 2017 (2017). Available at: https://aasarchitecture.com/2017/09/aia-coteselected-ng-teng-fong-general-hospital-sustainabledesign-excellence-

2017.html/?:+AAsArchitecture+(A+As+Architectur e). Accessed 25 Oct 2019 